\title{
Estimating trends of Atlantic meridional overturning circulation from long-term hydrographic data and model simulations
}

\author{
Gerrit Lohmann • Helmuth Haak • Johann H. Jungclaus
}

Received: 6 July 2007 /Accepted: 30 April 2008 / Published online: 24 June 2008

(C) The Author(s) 2008

\begin{abstract}
The ocean meridional overturning circulation (MOC) plays a central role for the climate in the Atlantic realm. Since scenarios for future climate change indicate a significant reduction of the MOC under global warming, an assessment of variations and trends of the real MOC is important. Using observations at ocean weather ship (OWS) stations and along oceanic sections, we examine the hydrographic information that can be used to determine MOC trends via its signature in water mass properties obtained from model simulations with the climate model ECHAM5/MPI-OM. We show that temperature trends at mid-latitudes provide useful indirect measure of large-scale changes of deep circulation: A mid-depth warming is related to MOC weakening and a cooling to MOC strengthening. Based on our model experiments, we argue that a continuation of measurements at key OWS sites may contribute to a timely detection of a possible future MOC slowdown and to separate the signal from interannual-tomultidecadal MOC variability. The simulations suggest that the subsurface hydrographic information related to MOC has a lower variability than the MOC trend measured directly. Based on our model and the available long-term hydrographic data, we estimate non-significant MOC trends
\end{abstract}

Responsible Editor: Jin-Song von Storch

G. Lohmann $(\bowtie) \cdot$ H. Haak

Alfred Wegener Institute for Polar and Marine Research,

Bussestr. 24,

27570 Bremerhaven, Germany

e-mail: Gerrit.Lohmann@awi.de

H. Haak · J. H. Jungclaus

Max-Planck Institute for Meteorology,

Bundesstr. 53,

20146 Hamburg, Germany for the last 80 years. For the twenty-first century, however, the model simulations predict a significant MOC decline and accompanied mid-depth warming trend.

Keywords Ocean circulation - Ocean weather ship stations . Atlantic meridional circulation $\cdot$ Temperature trends

\section{Introduction}

A major unknown in assessing global change is the future fate of the world ocean. Climate model experiments suggest that the Atlantic meridional overturning circulation (MOC) and its associated heat transport may weaken under global warming conditions in the twenty-first century (IPCC 2007). The MOC consists of deep convection from surface cooling at high latitudes, equatorward flow of the resulting deep water, and upwelling of deep water at lower latitudes. Paleoclimate proxy records suggest that massive and abrupt climate changes have occurred in the Northern Hemisphere, especially during and just after the last glacial, with MOC changes as the most plausible mechanism (e.g., Broecker and Denton 1989; Alley et al. 2003; McManus et al. 2004). By analogy with paleoclimatic reconstructions, it is possible that such a MOC perturbation would have an impact on future climate, e.g., by influencing the global cycle of uptake, release, and storage of carbon.

Analyzing hydrographic records between the 1950s and 1990s, it has been suggested that North Atlantic Deep Water (NADW) have steadily become warmer (Levitus et al. 2000; Arbic and Owens 2001) and less saline (Dickson et al. 2002; Curry et al. 2003; Curry and Mauritzen 2005), which could have affected the MOC. However, it is neither straightforward to trace MOC weakening under global warming conditions nor to detect if it is already in progress. 
Observation-based estimates of MOC strength are given by Roemmich and Wunsch (1985) and Ganachaud and Wunsch (2000). However, the existing hydrographic measurements are too sparse to obtain a time evolution in the mass budgets. In order to systematically measure the MOC strength, moored instrument arrays have been deployed at transatlantic sections (Hirschi et al. 2003, Baehr et al. 2004). MOC monitoring at $26.5^{\circ} \mathrm{N}$ was also recently reported in Cunningham et al. (2007) and Kanzow et al. (2007). Of particular relevance to the focus on temperature and salinity responses to MOC changes, Cunningham and Alderson (2007) diagnose the vertical structure of changes in temperature and salinity at $24.5^{\circ} \mathrm{N}$ and discuss how these changes may be linked to MOC slowdown reported by Bryden et al. (2005). Bryden et al. (2005) used ship-based hydrographic transects along $24.5^{\circ} \mathrm{N}$ from 1957, 1981, 1992, 1998, and 2004. Missing data and natural climate variations on time scales from days to centuries make MOC estimates extremely difficult (Von Storch and Haak 2008).

Mooring array programs have only recently been established, and their observational record is too short to draw a conclusion about MOC trends since the ocean circulation is also masked by strong variability on subannual to interdecadal timescales (e.g., Cunningham et al. 2007; Dima and Lohmann 2007). As a different approach, Levermann et al. (2005) suggest that the observed changes in sea level can be effectively used for monitoring the strength of MOC. Others propose to use the surface signature in temperature and precipitation (Lohmann 2003; Latif et al. 2004; $\mathrm{Hu}$ et al. 2004) for estimating changes in MOC. Disadvantages of these methods may be that other phenomena project on the signature (e.g., northsouth gradient or "interbasin" balances) and the derived indices are partly different from MOC trends.

Here, we propose a different approach to use long-term hydrographic data. The World Ocean Circulation Experiment (WOCE) was a component of the World Climate Research Program and remains the most ambitious oceanographic experiment undertaken to date. The field phase of the project lasted from 1990 to 1998 . On the completion of WOCE, a global study of the Earth's climate variability and predictability (CLIVAR) is being actively pursued. In the present paper, we trace circulation trends based on long-term quality-checked observational temperature and salinity data in combination with climate scenario simulations. The climate model experiments are used to derive characteristic temperature and salinity patterns of MOC weakening along hydrographic sections (WOCE-CLIVAR) and station data at weather ships (OWS) in the North Atlantic. The ocean weather station idea originated in the early days of radio communications and transoceanic aviation. Oceanographic observations were recommended for weather ships almost from the start $\sim 1910$ (e.g., temperature and salinity profiles).
As we find out, the information of the whole water column at these stations is necessary to detect ocean circulation trends and to separate them from natural climate variability. These characteristic patterns are used to estimate the past 100 years of MOC trends, which is important to bring recent data and predicted changes into a long-term context. The use of the long-term observations provided by the OWS bring the more recent data related to MOC into the long-term context.

\section{Methodology}

\subsection{Model}

The climate model simulations were conducted with a full coupled atmosphere-ocean-sea ice general circulation model: ECHAM5/MPI-OM. The model has no flux corrections and has been tested for several applications under present day conditions (Latif et al. 2004; Jungclaus et al. 2005, Jungclaus et al. 2006a). The atmospheric part of the model, ECHAM5 (Roeckner et al. 2003), has a horizontal resolution of $1.875^{\circ}$ by $1.875^{\circ}$ (T63) and 31 vertical levels. The ocean/sea ice part of the model, MPI-OM (Marsland et al. 2003), has a $1.5^{\circ}$ by $1.5^{\circ}$ horizontal resolution on a curvilinear grid (see Fig. 1), with 40 vertical levels.

\subsection{Simulations}

The simulations were carried out for the period 1860-2100 in the framework of the fourth Assessment Report of the Intergovernmental Panel on Climate Change (IPCC) published in 2007. The model was initialized from the end of a pre-industrial control experiment and then forced with observed greenhouse gas and aerosol concentrations for the period 1860-2000 (20C Experiment). Thereafter, greenhouse gas and aerosol concentrations followed different scenarios (A1B, A2, and B1 Experiments). A summary of the forcing functions for the scenarios $\mathrm{A} 2, \mathrm{~B} 1$, and $\mathrm{A} 1 \mathrm{~B}$ can be found in the IPCC report (IPCC 2007). Experiment 20C has been continued with fixed emissions for the twenty-first century at values from year 2000 AD.

\subsection{Hydrographic sections and Ocean Weather Ship stations}

For the sections in the Atlantic Ocean (Fig. 1), repeated measurements across major current systems and interbasin channels have been made in WOCE and CLIVAR in order to document interannual and longer period changes in circulation. In our analysis, section A17 has been extended to the northern North Atlantic in relation to the WOCECLIVAR definition in order to include more information in the meridional direction. The detailed structure of the 


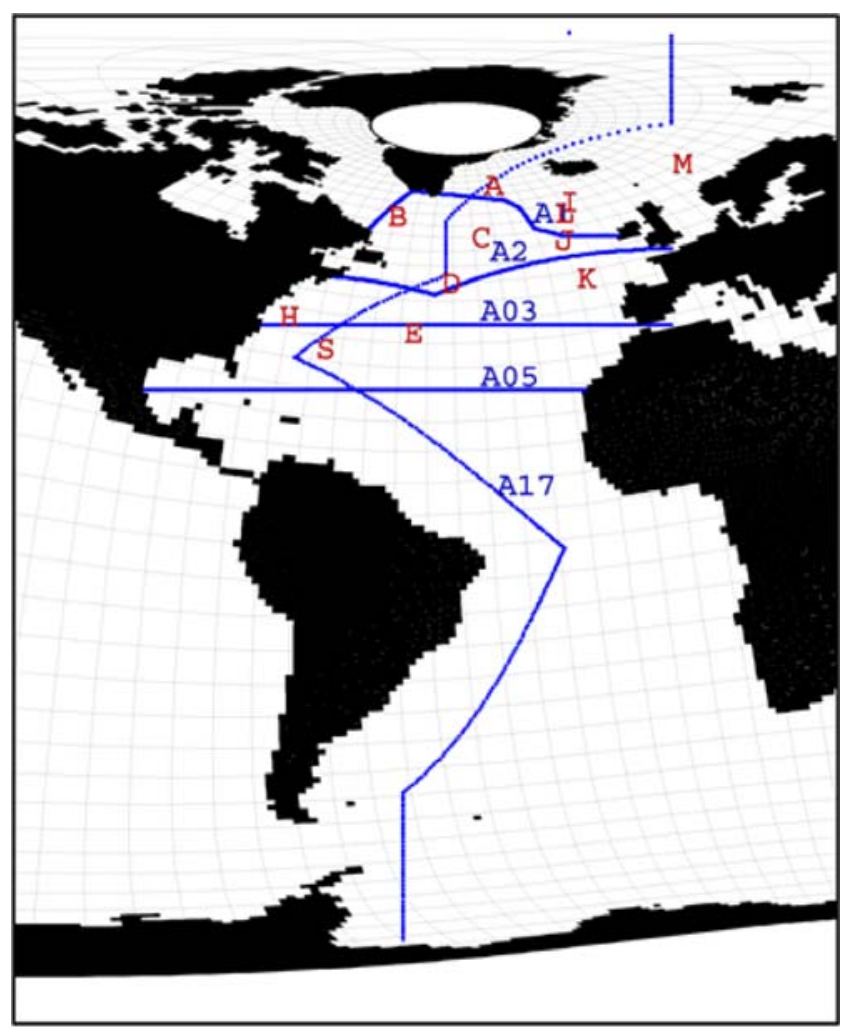

Fig. 1 Sections and stations used: zonal sections $\mathrm{A} 01$ at $55^{\circ} \mathrm{N}, \mathrm{A} 02$ at $50^{\circ} \mathrm{N}, \mathrm{A} 03$ at $36^{\circ} \mathrm{N}, \mathrm{A} 05$ at $24^{\circ} \mathrm{N}$, and meridional section A17 along the western Atlantic Ocean; sites from ocean weather ships where long-term observations are available are indicated as letters. Ocean model grid lines are plotted every fifth grid box

section is, however, of minor importance for our results. Other data sets, e.g., satellite altimetry and ARGO profiling floats, are not considered in our analysis.

The hydrographic database (Curry 2002) includes longterm OWS data in combination with more recent section and station measurements. For our analysis, we have used the quality-checked data (Curry 2002; Curry et al. 2003). For OWS E, we applied an area average over $\left(50-46^{\circ} \mathrm{W}\right.$; $33-37^{\circ} \mathrm{N}$ ) covering the period 1910-1993; for OWS S, an area average over $\left(66-62^{\circ} \mathrm{W} ; 30-34^{\circ} \mathrm{N}\right)$ covering the period 1914-1989. In order to examine the regressions and ocean circulation (re-)constructions, we interpolate the station data to the 40 vertical model levels.

\section{Results}

\subsection{Model climate and scenario integrations}

For 20C, we show some hydrographic sections and stations in the model. Figure 2a and $\mathrm{b}$ show the 1860-2000 average potential temperature and salinity at WOCE-CLIVAR section A17. The large-scale water masses like NADW, Antarctic
Bottom Water, or Antarctic Intermediate Water are represented reasonably, although local differences of their properties from observations can be considerable. Also shown is the meridional overturning stream function for the same period (Fig. 2c), indicating a maximum of $22 \mathrm{~Sv}\left(1 \mathrm{~Sv}=10^{6} \mathrm{~m}^{3} / \mathrm{s}\right)$ at $45^{\circ} \mathrm{N}$ and a standard deviation of $1 \mathrm{~Sv}$ in respect to annual mean values for the years 1860-2000. The Atlantic outflow is $17 \mathrm{~Sv}$ at $30^{\circ} \mathrm{S}$, and the ocean heat transport is $1.15 \mathrm{PW}$ at $20^{\circ} \mathrm{N}$. Additional aspects of the model performance are discussed elsewhere (van Oldenborgh et al. 2005; Jungclaus et al. 2006a). Figure 3 shows simulated and observed potential temperatures at OWS S. The figure indicates a general agreement between observations and model but a too warm intermediate to deep ocean.
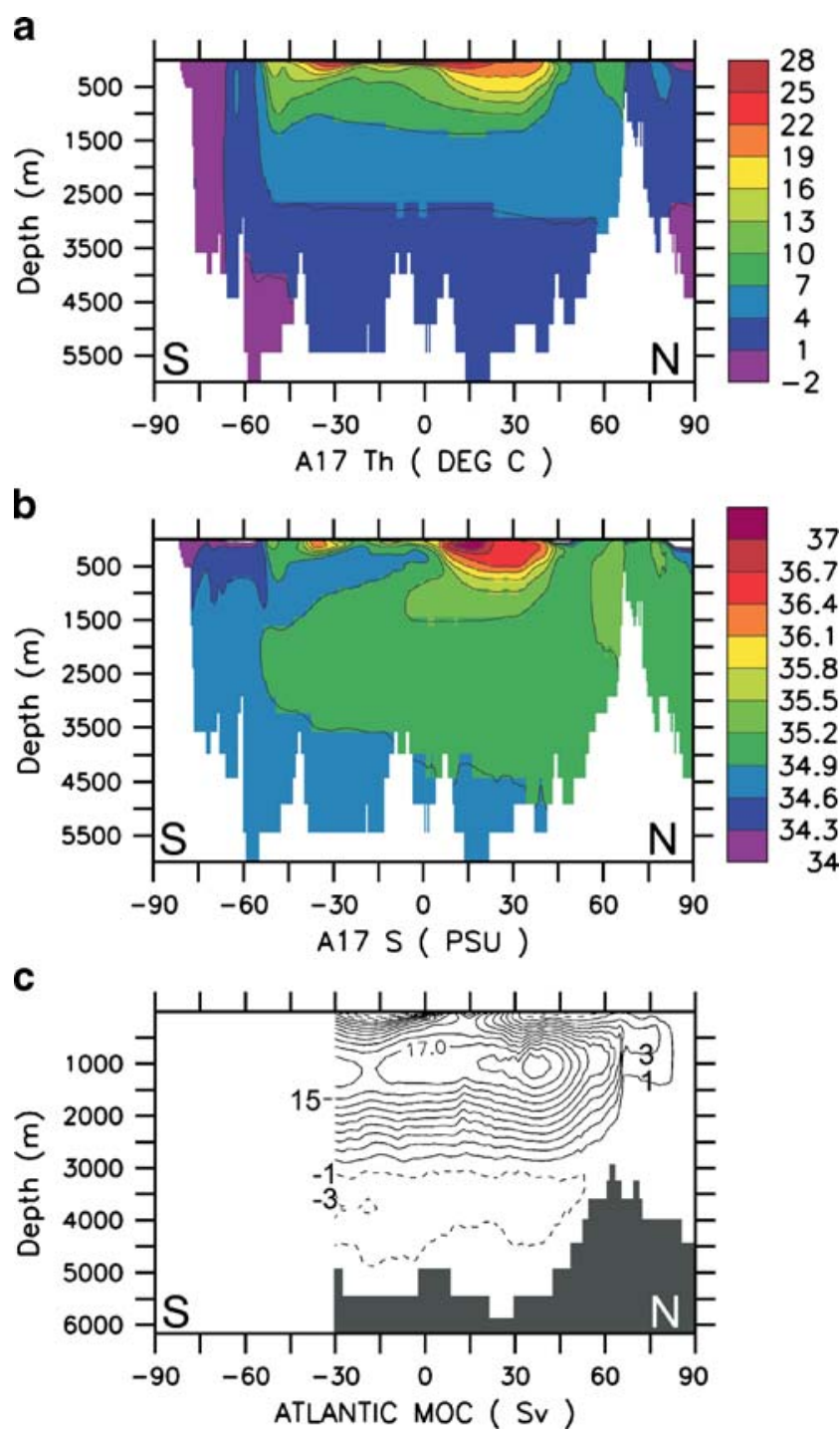

Fig. 2 a, b Section A17 temperature (degree Celsius) and salinity (practical salinity unit) for the period 1860-2000 in the model. c Modeled Atlantic overturning stream function $\left(\mathrm{Sv}=10^{6} \mathrm{~m}^{3} / \mathrm{s}\right)$ 


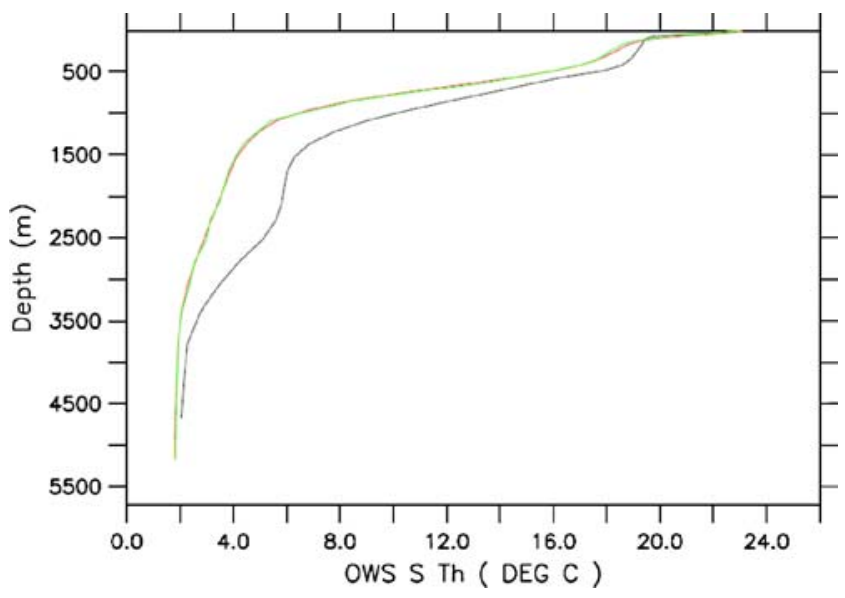

Fig. 3 Simulated (black line) and observed (colored lines) potential temperature at OWS S. Observations are CTD (conductivity, temperature, and pressure instrument) data (red line) and bottle data (green). (Red and green lines are nearly identical, and the red line is, therefore, hardly seen.) Period is 1860-2000 AD for the simulation, 1914-1998 for the bottle data, and 1985-1999 for the CTD data (Curry 2002)

Simulated annual mean global surface temperature for different ensemble members are shown in Fig. 4a, together with the corresponding observations by Jones et al. (2001). Note that temperature curves are normalized with respect to the period 1961-1990. The ensemble of twentieth century integrations agrees well with the observations in terms of variability and the warming trend over the last decades of the twentieth century. Note that the continuation of the $20 \mathrm{C}$ experiments into the twenty-first century with emissions fixed at year 2000 values indicate a very moderate warming for the twenty-first century (Fig. 4a).
The time evolution of the Atlantic maximum meridional overturning stream function is shown in Fig. 4b (annual mean values). The seasonal MOC strength has a standard deviation of appr. $3 \mathrm{~Sv}$ in our simulation, but in the following, we concentrate on the annual mean values. The meridional overturning for A1B shows a weakening of $5 \mathrm{~Sv}$ from year 2000 to 2100 due to warming and freshening of high-latitude surface water. We find, though the large-scale MOC structure seen in Fig. 2c is not affected, considerable changes in the deep water formation regions and their relative role (not shown). It is interesting to note that the run $20 \mathrm{C}$ shows a very moderate MOC reduction for the twenty-first century, but an in-depth discussion is not within the scope of this paper. For our further analyses, we concentrate on the SRES A1B scenario (IPCC 2007), which is a scenario with a moderate climate response (Fig. 4a) and with an overturning response similar to that of $\mathrm{A} 2$ and $\mathrm{B} 1$ in the twenty-first century (cf. Fig. 4b).

\subsection{Regression analyses}

The simulated WOCE-CLIVAR hydrographic sections, as well as temperature and salinity profiles at the OWS sites, are regressed against the time series of annual mean MOC strength for the period 1860-2000. We take the MOC maximum rather than the value at a fixed latitude (results related to $30^{\circ} \mathrm{N}$ give similar results). Since the simulated annual mean MOC has a standard deviation of $1 \mathrm{~Sv}$, the normalized overturning index (MOI) and anomalous overturning strength (in units of sievert) can be associated with each other. The regression patterns are used to obtain a MOI signature pattern. The temperatures to MOI regres-
Fig. 4 a Simulated annual mean global surface temperature for different IPCC scenarios with three ensemble members. Temperature curves are normalized with respect to the period 1961-1990. Observed temperatures are shown as dashed black lines for comparison (Jones et al. 2001). b The MOC for A1B shows a weakening of $5 \mathrm{~Sv}$ from year 2000 to 2100 . Scenarios A2 and $\mathrm{B} 1$ are very similar to that of $\mathrm{A} 1 \mathrm{~B}$. The run $20 \mathrm{C}$ shows a very moderate MOC reduction for the twenty-first century
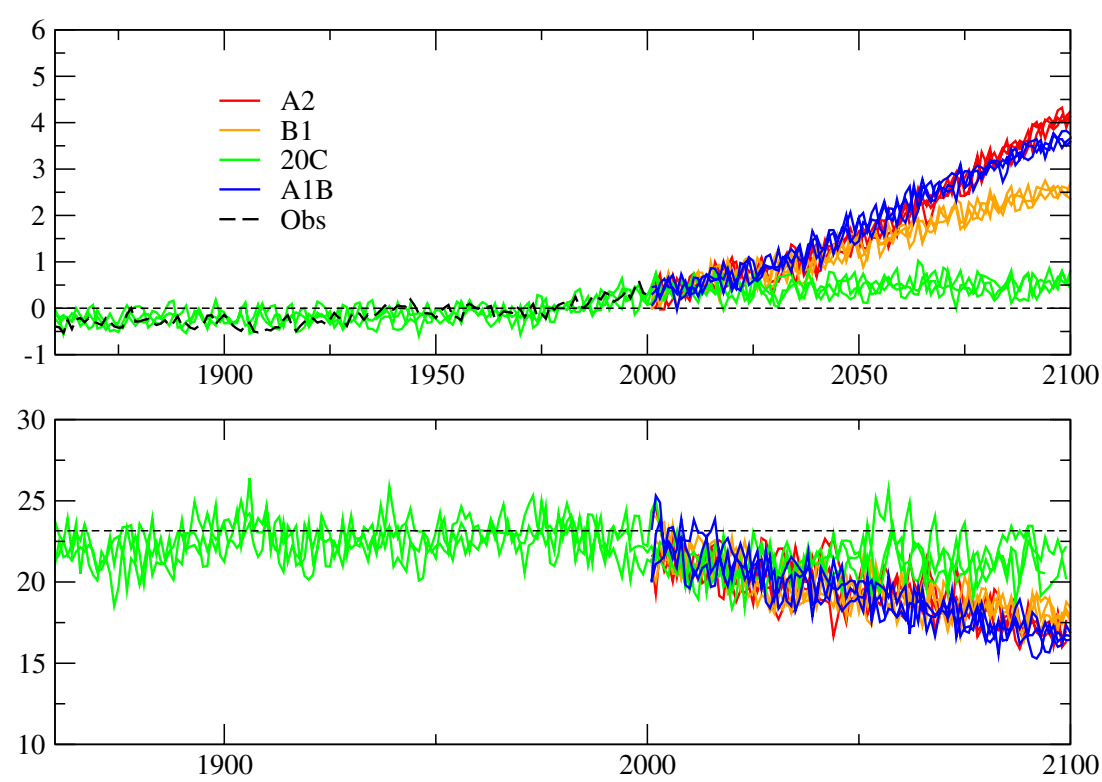
sions for the period 1860-2000 are calculated but only shown for OWS S (Fig. 5a) and OWS E (Fig. 6a). The later analysis will show that the information from the other sites cannot be used to estimate MOC trends.

The temperature regression at OWS S has three minima at $500,1,500$, and $2,500 \mathrm{~m}$, indicating cold conditions when there is a strong MOC (Fig. 5a). The pattern is close to the baroclinic first mode as described by Cunningham and Alderson (2007). The changes in the $300-800 \mathrm{~m}$ are related to the thermoclince, the second peak between 900 to $1750 \mathrm{~m}$ is related to intermediate water, 1,750 to $2,500 \mathrm{~m}$ is related to upper North Atlantic Deep Water, and below that is lower Atlantic Deep Water. A decrease in MOC is related to temperature increase (Fig. 5a), which is dominated by isopycnal heave. The temperature trend analysis (Figs. 5b, $6 \mathrm{~b})$ for the period 2000-2100, when the MOC weakens, shows a warming in the upper $2,000 \mathrm{~m}$. The temperature

a

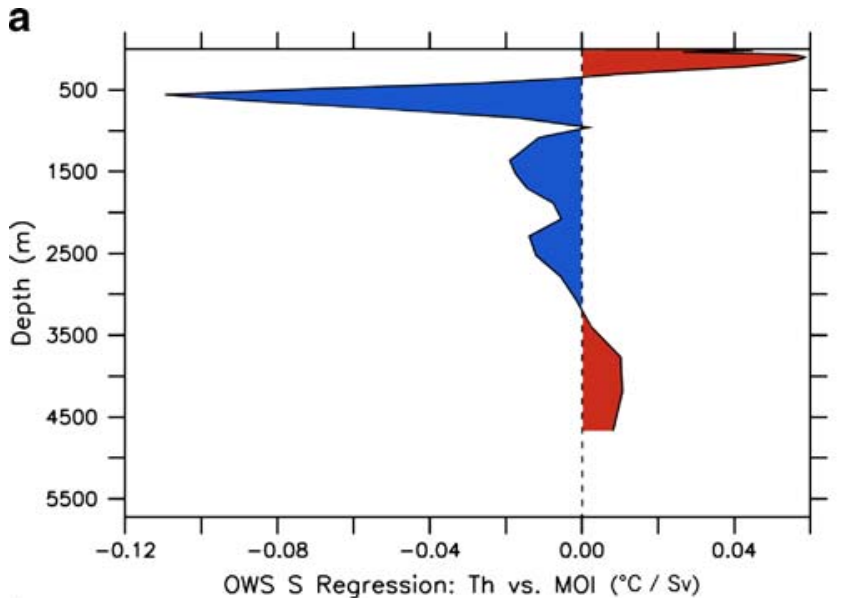

b

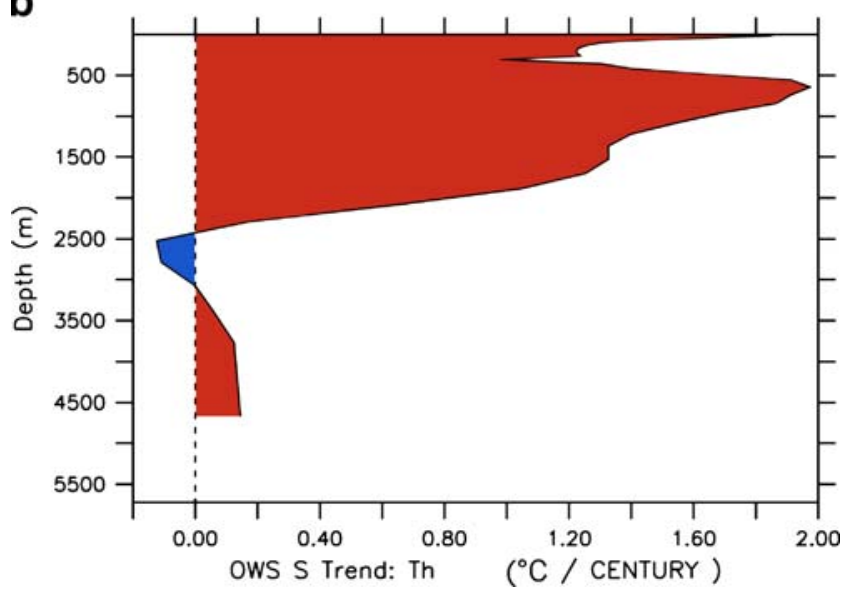

Fig. 5 a Regression of potential temperature at the OWS S location versus MOC (degree Celsius per Sv) in the simulation for the years 1860-2000 AD. b Trend of potential temperature at the site OWS S as simulated for the years $2000-2100$
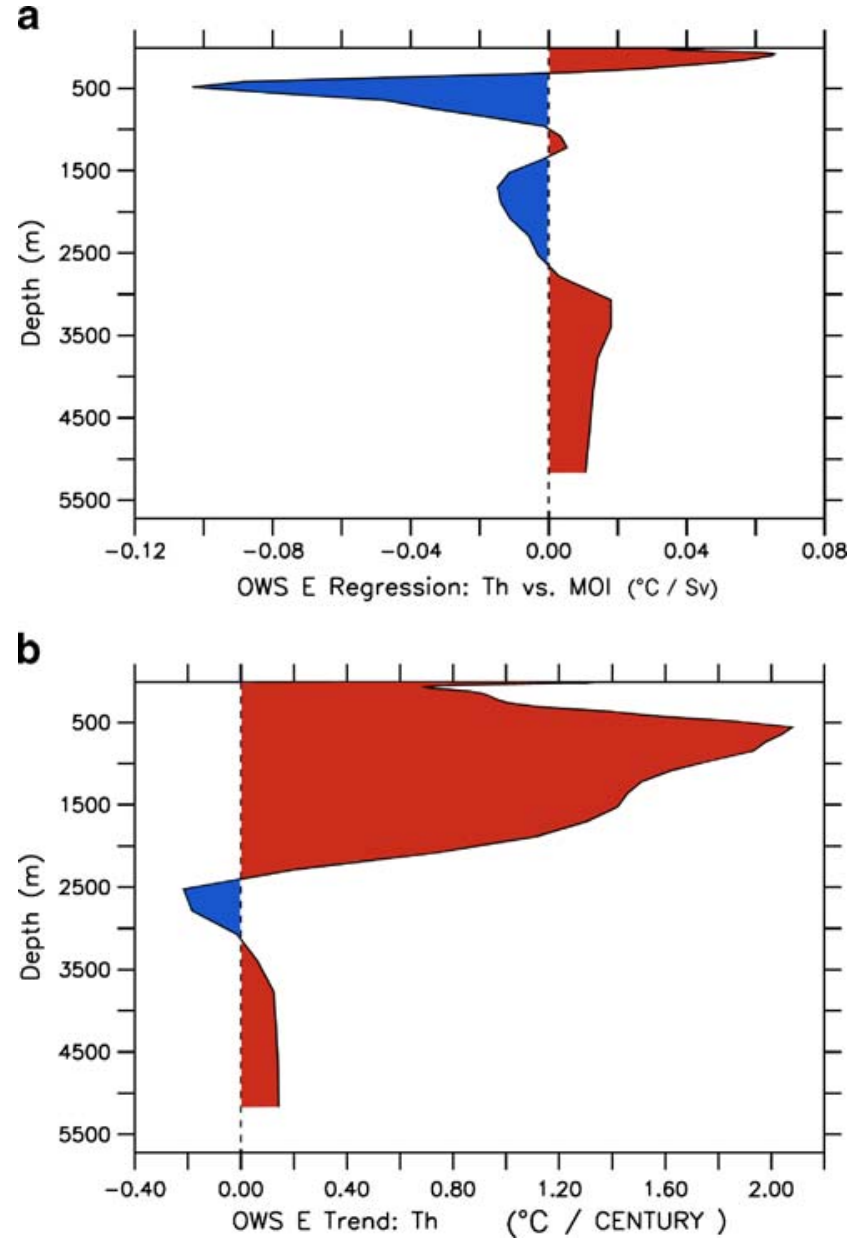

Fig. 6 a, b The same as Fig. 5, but for OWS E

variability is relatively small at mid-depth $(700-2,200 \mathrm{~m})$, which could be used for an optimized signal-to-noise analysis (not shown). In the upper $1,000 \mathrm{~m}$, temperature variability is highly dominated by interannual-to-decadal variability (not shown).

The regression of temperature $\theta$ and salinity $S$ to MOC strength is evaluated at the cross-section A17 for the period 1860-2000 (Fig. 7a,c). A strong MOC is associated with a relatively warm salty surface ocean between $50^{\circ}$ and $80^{\circ} \mathrm{N}$, a relatively warm salty downward MOC branch between $45^{\circ}$ and $60^{\circ} \mathrm{N}$ in 3,000-m depth, and a moderately cool fresh layer at 100 to $2,500-\mathrm{m}$ depth in the tropical and subtropical Atlantic Ocean. The latter temperature is due to inflow of cold intermediate and deep water masses from the north. The same argument is seen for the mid-latitude OWS at these depths.

The section A17 temperature trend analysis (Fig. 7b) shows a general warming, as expected from the increasing 

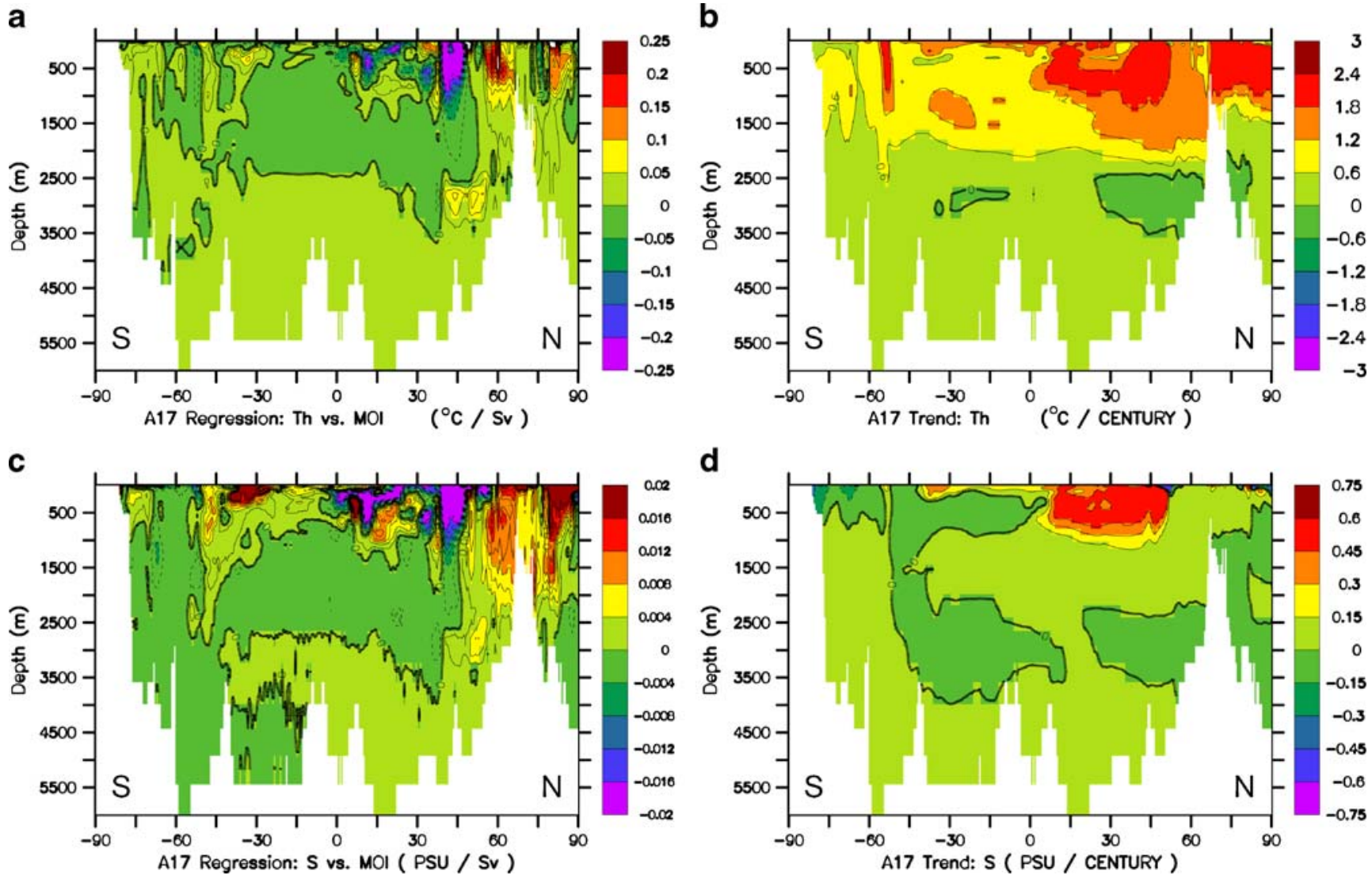

Fig. 7 a Regression of potential temperature across A17 versus MOI in the simulation for the years 1860-2000 AD. b Trend of potential temperature in the simulation across A17 for the years 2000 to $2100 \mathrm{AD}$. c, d The same as a, b, but for salinity

atmosphere greenhouse gases. The warming trend at intermediate depths, which is accompanied by a cooling in the downward branch of the North Atlantic Deep Water, is associated with Atlantic MOC weakening during this period. The A17 salinity trend analysis (Fig. 7d) is determined by enhanced evaporation in the subtropics in conjunction with high-latitude freshening and projects not directly onto the MOC trend.

Regression and trend analysis for the zonal section A05 are shown in Fig. 8. During times of high MOC, an anomalous zonal temperature and salinity gradient in the upper $1,000 \mathrm{~m}$ is detected: cooling and freshening in the west with a warming and increase in salinity in the east. The east-west asymmetry in salinity is also consistent with the anomalous surface salinity (not shown). The anomalous zonal hydrography is directly linked to the overturning circulation. The trend pattern (Fig. 8b,d) stems from an anomalous increase in the east relative to the west.

\subsection{Constructing the overturning trends}

In the model, the hydrographic evolution for $\theta$ and $S$ is converted to the MOI using the regression patterns $r$ shown in Figs. 5a, 6a, 8a-c, and 9a,b. To give an example for OWS E, the potential temperature evolution $\theta(z, t)$ is multiplied for each level with $r^{-1}(z)$ and summed over all $z$ levels to get the evolution in the anomalous MOI. This procedure is called construction of the MOI through the hydrographic evolution (in the model).

Since $r$ is based on period 1860-2000, it is not surprising that the derived meridional overturning indices (the colored lines) are similar to the simulated MOI (shown as the black line in Fig. 10). A comparison of the simulated MOI with the MOI as derived from stations and sections shows that some stations and sections can be used to predict the MOC trend for the period 2000-2100. For the OWS stations, the OWS E and OWS S regression of potential temperature provide reasonable approximations to construct the MOC trend (Fig. 10a), whereas the salinity-based MOI construction at all OWS sites do not project onto MOC trends (Fig. 10b). For the WOCE-CLIVAR sections, the temperature at the A17 section can be used as a fingerprint to construct MOC trends (Fig. 10c). In contrast to the meridional salinity structure along A17, the zonal subtropical section A05 in salinity is associated with the MOC dynamics (Fig. 10d). The strong trend in subtropical 
a
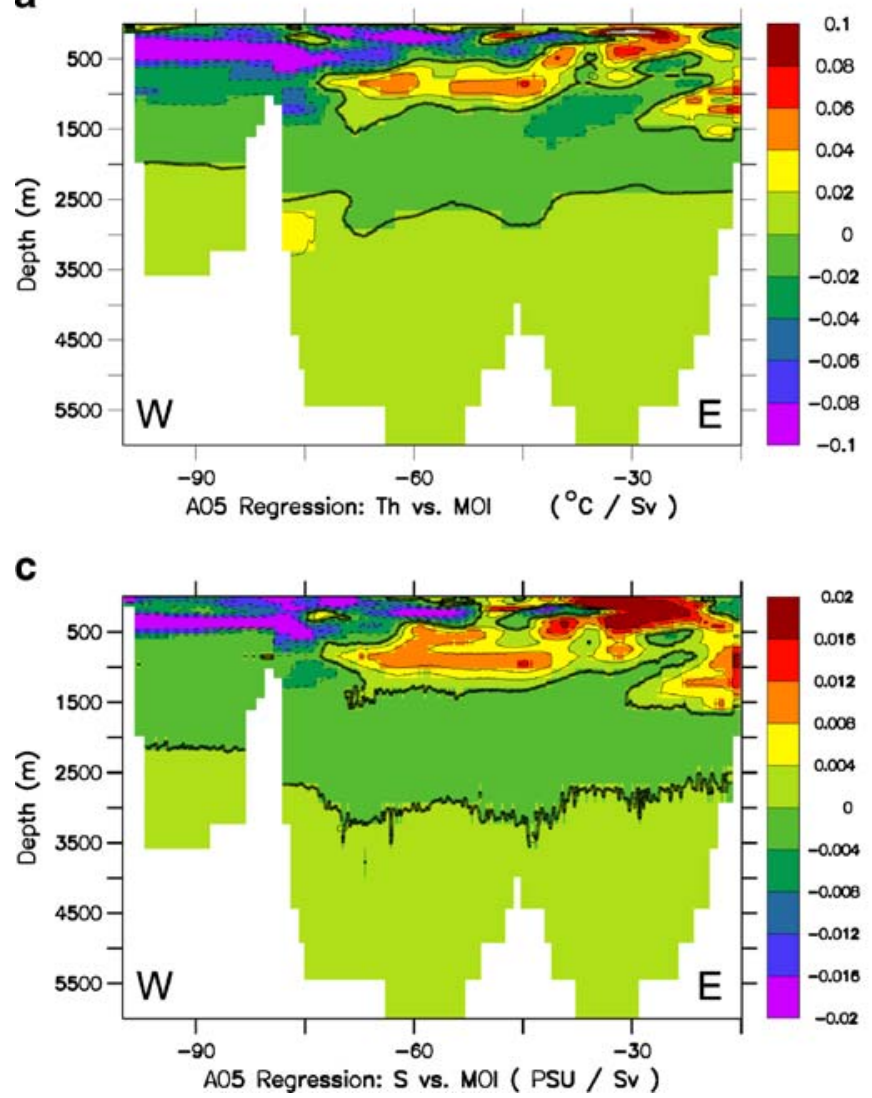

Fig. 8 The same as Fig. 7, but for the zonal section A05

salinity (Fig. 8d) is consistent with the horizontal salinity distribution. For all trends of the constructed MOI, we refer to Fig. 9. In this figure, we see that some of the stations even do not show the right sign (a MOC weakening). This shows that this information cannot be used for the (modeled) construction of MOC trend.

In order to quantify the potential of the different sections to predict the MOC trend for the period 2000 to $2100 \mathrm{AD}$, we plot the error between the constructed and the simulated MOI trend (Fig. 11). The value of one would mean that the constructed MOI trend overestimates the overturning decline by $1 \mathrm{~Sv} / 100$ years. Furthermore, the standard deviation ratio between simulated MOI and constructed MOI is displayed. A value less than 1 mean that the standard deviation of the constructed MOI is smaller than the simulated MOI.

The analysis reveals that the temperatures at OWS E and OWS S, as well as temperatures at section A17, provide useful indirect measure of large-scale changes of deep circulation, with a standard deviation even smaller than the simulated MOC. The reason for the smaller standard deviation could be that the MOC is affected by the
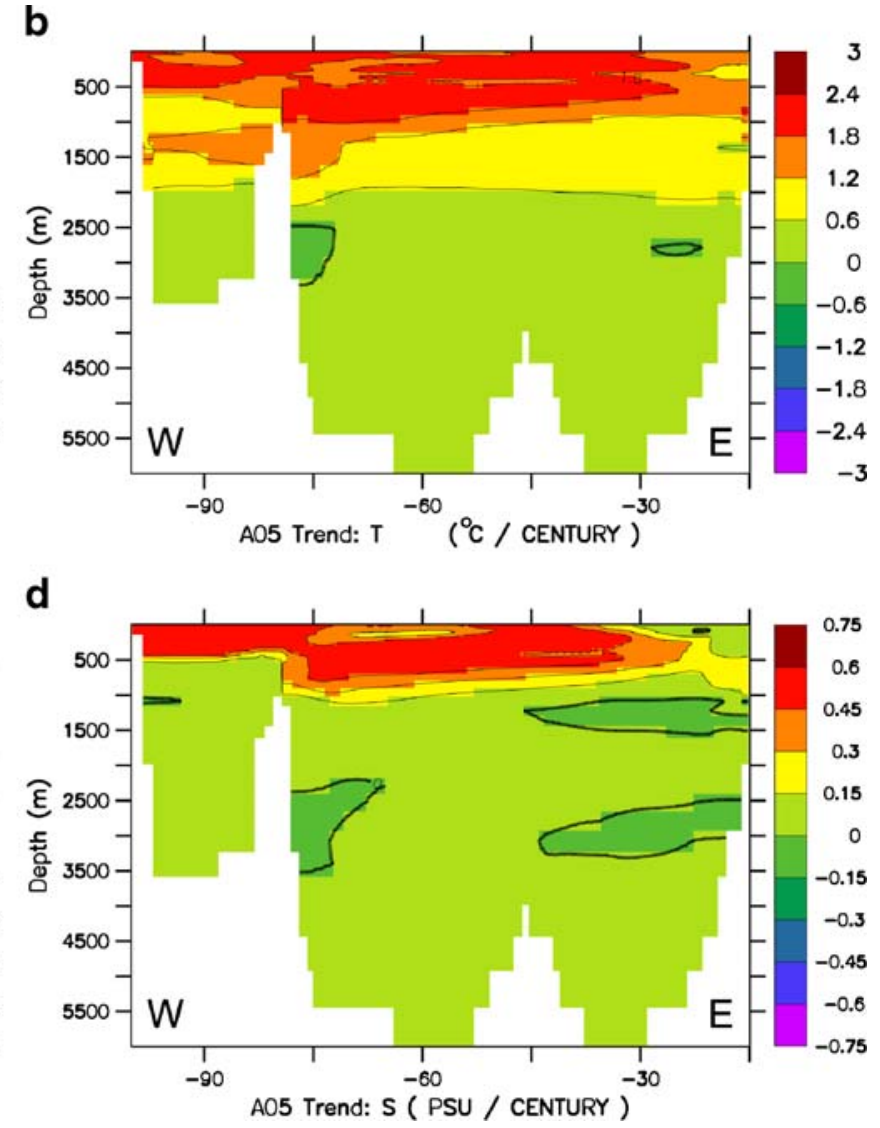

atmospheric noise (e.g. the North Atlantic Oscillation), whereas the subsurface quantities see already a reduced noise integrated by oceanic processes (e.g., through vertical mixing, advection). The atmospheric forcing can contribute to decadal MOC variations via Labrador Sea Water (Haak 2004) and mask longer-term MOC trends (Delworth and Dixon 2000; Vellinga and Wood 2004).

Via the described regression technique, observed temperature information from OWS E and OWS S (Curry 2002) are used to derive a 1900-2100 MOI time series through projection of hydrographic changes onto the model-derived MOI fingerprints of Figs. 5a and 6a. Figure 12 indicates small non-significant trends in the observational-based MOI for the last 80 years, which is also in line with the model simulation (Fig. 2b). Similarly, the simulation-based MOI at OWS E and OWS S show almost no MOC trend for the last 100 years but a decrease of about $5 \mathrm{~Sv}$ over the next 100 years. For the last decades, there is a moderate warming at mid-depth possibly associated with a small MOC decrease (Fig. 12). From the modeled hydrographic data, we estimate the time at which the uncertainty cross the two standard deviations-threshold is reached as the year 2070 . 


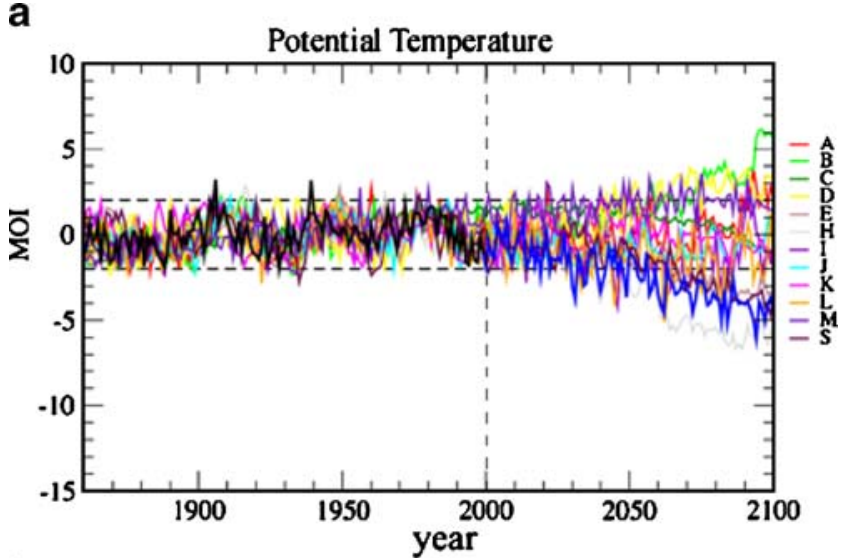

b

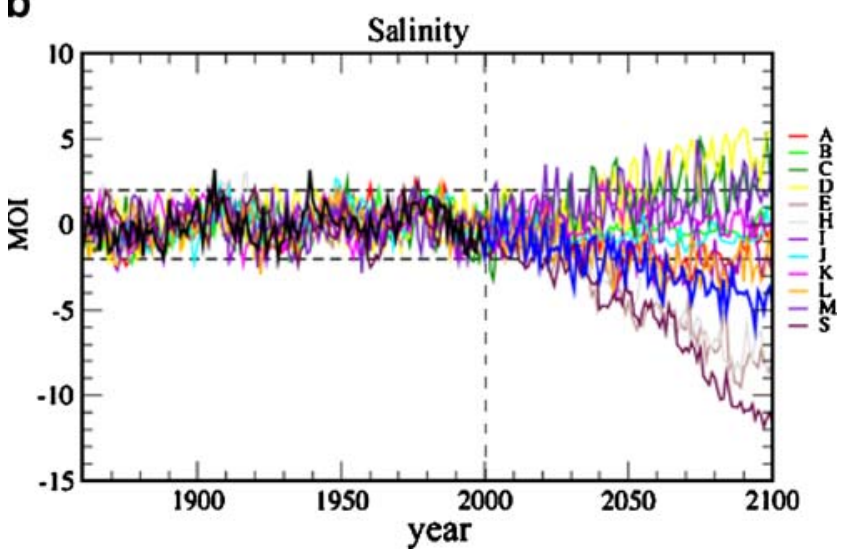

Fig. 9 Simulation-based MOI (black and blue lines) and reconstructed MOI (other colors) for the stations in Fig. 1. a Potential temperature, b salinity. Since the simulated MOI has a standard deviation of $1 \mathrm{~Sv}$, the normalized overturning index and anomalous overturning strength (in units of Sv) can be associated with each other

\section{Discussion}

In our analysis, we extend the analysis to the last century but rely of course on the model's ability to simulate the hydrographic changes with MOC. We admit that the modeled and observed temperature structure is not identical. We find, however, that the structure of temperature changes with MOC is a robust feature in our simulations and that the principal temperature structure (mid-depth warming for MOC reduction) are similar when looking at different model simulations (Rühlemann et al. 2004; Drijfhout and Hazeleger 2006) and even model intercomparison using the same forcing function (Stouffer et al. 2006).

Our integrated temperature indicator of $\mathrm{MOC}$ trend (based on the whole water column) has an error of less than $1 \mathrm{~Sv}$ within one century (Fig. 11), although the regression error at each depth can be higher. From Fig. 12, we derive the conclusion that there is no significant MOC trend over the last century. However, if one looks at shorter periods like 1960-2000, one may come to the conclusion of a moderate MOC decline, which could be part of decadal variability. This would be consistent with Cunningham and Alderson (2007), indicating mid-depth warming for that period (their Fig. 2a) caused by an upward motion of the isopycnals. The hydrographic change in A05 (Fig. 8) is also consistent with an increase in salt in the west and reduced salinity in the east for the last decades (Cunningham and Alderson 2007). The sections A1, A2, and A3 turn out to be less useful for constructing MOC trends and could be more related to with the changes in thermocline thickness implied by the temporal changes in Ekman pumping (Leadbetter et al. 2007).

For the time when hydrographic data is available, our method should be combined with direct calculations of the MOC strength or direct estimates of mass transports based on velocity measurements and hydrographic fields (e.g., Hirschi et al. 2003; Bryden et al 2005; Baehr et al. 2004, 2007a, b; Cunningham et al. 2007), as well as indirect methods (Latif et al. 2004; Hu et al. 2004; Levermann et al. 2005). Global inverse calculations from hydrographic observations or other volume transport estimates typically yield a standard error of 2-6 Sv in the MOC strength (Roemmich and Wunsch 1985; Ganachaud and Wunsch 2000; Ganachaud 2003; Smethie and Fine 2001; Bryden et al. 2005). Furthermore, detecting MOC changes needs to account for both variability and observational uncertainty.

One should mention two principal problems for MOC construction. The noise is relatively high for intra-annual variations; therefore, the use of annual mean values of stations and arrays is preferred. It could be that the much more noisy 'real' observed station and cross-section data would cause a detection of MOC slowdown to occur much later than indicated by the idealized model case. The variance of the hydrography at the OWS sites is lower in the model as compared to the measured data (not shown). We speculated that this could be due to not continuous measurements for the real observations and/or model deficits. In our case, it appears, however, that the MOI values based on modeled and measured hydrography at OWS $\mathrm{E}$ and OWS $\mathrm{S}$ have almost the same variance (Fig. 12). The usual problem of calculating MOC from observations (hydrographic and velocity measurements) is transferred in our approach to the models' ability to simulate the temperature and salinity responses to MOC changes. It would be interesting to check the robustness in other IPCC runs showing also a MOC decline for the next century (IPCC 2007).

The MOC trends for the twenty-first century are only reconstructed correctly in $10 \%$ of the cases. From a statistical point of view, one may argue that this is a pure mathematical artifact. However, we underline that the temperature response due to $\mathrm{MOC}$ trend has a clear 
a

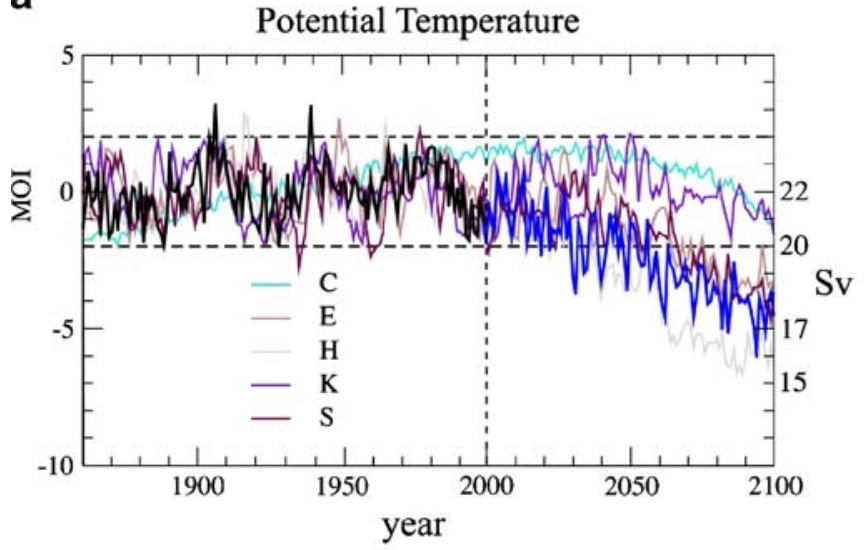

C

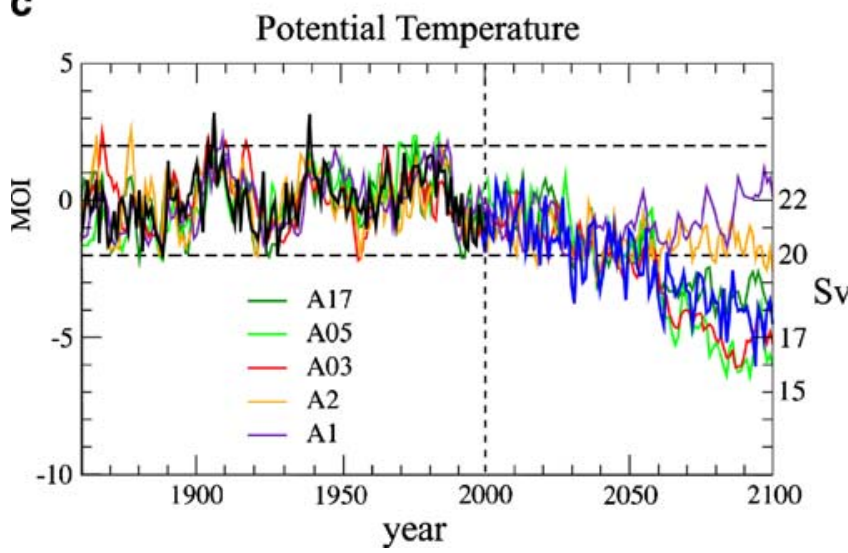

Fig. 10 Simulation-based MOI (black and blue lines) and reconstructed MOI (other colors) for the sections and stations in Fig. 1. a Potential temperature for the stations, b salinity for the stations. For

physical reason: Less advection of cold high-latitude water in the North Atlantic causes a mid-depth warming in the tropical and subtropical North Atlantic. Such mechanism has been shown to be valid for MOC reductions in the geological past induced by deglacial meltwater and moderate Holocene sea surface salinity variations (Rühlemann et al. 2004).

The AR4 simulations did not take into account any additional freshwater input from the melting Greenland ice sheet. Mass balance calculations (Huybrechts et al. 2004) estimate an input of about $6 \times 10^{-3} \mathrm{~Sv}$ in the year 2100 . The most recent estimates tend to be larger (e.g., Rignot and Kanagaratnam 2006), suggesting that freshwater input by 2100 could be considerably larger. Sensitivity experiments (Jungclaus et al. 2006b) showed an additional reduction of the MOC but even for an upper estimate of fresh water forcing; the MOC evolution in the twenty-first century was close to the baseline scenario.

Another difficulty of observational and model-based methods is that the ocean shows transient behavior and
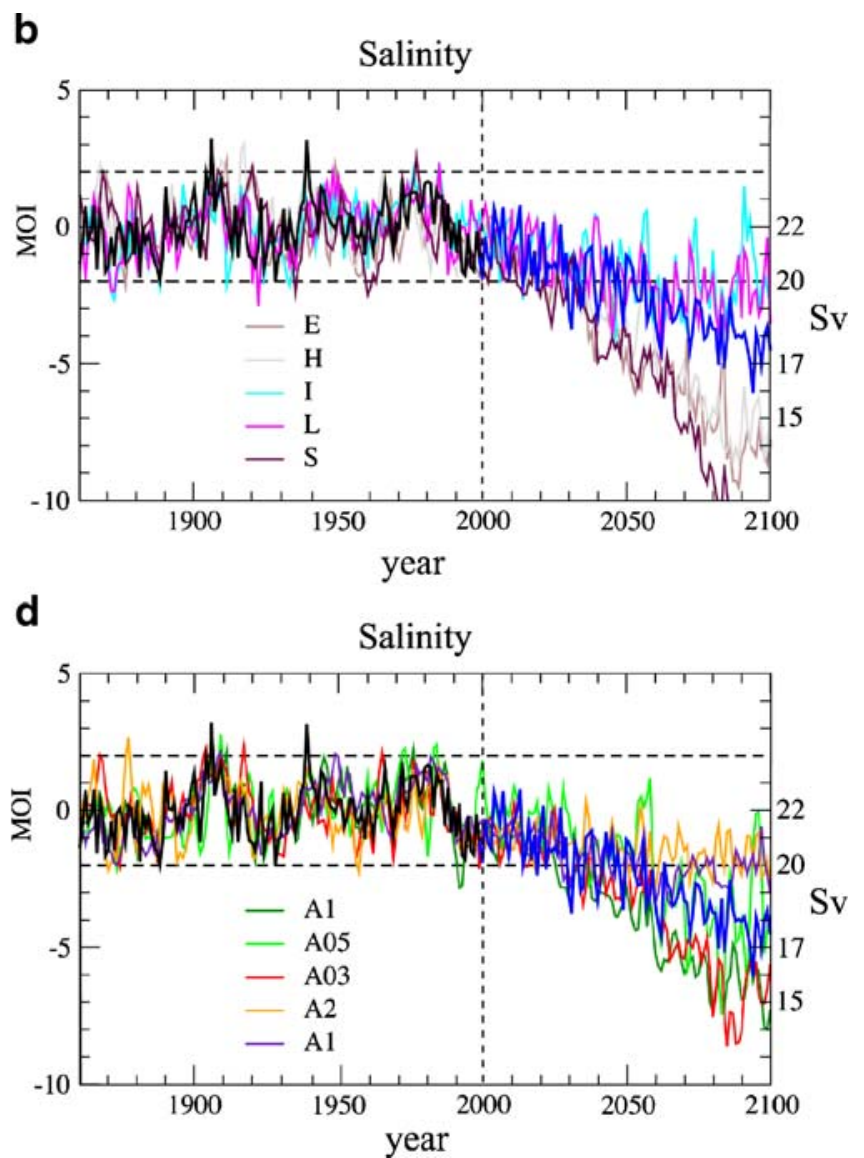

clarity in $\mathbf{a}$ and $\mathbf{b}$, only the MOI constructions are retained, which show a decrease in MOC for the period 2000-2100. c Potential temperature for the sections, $\mathbf{d}$ salinity for the sections

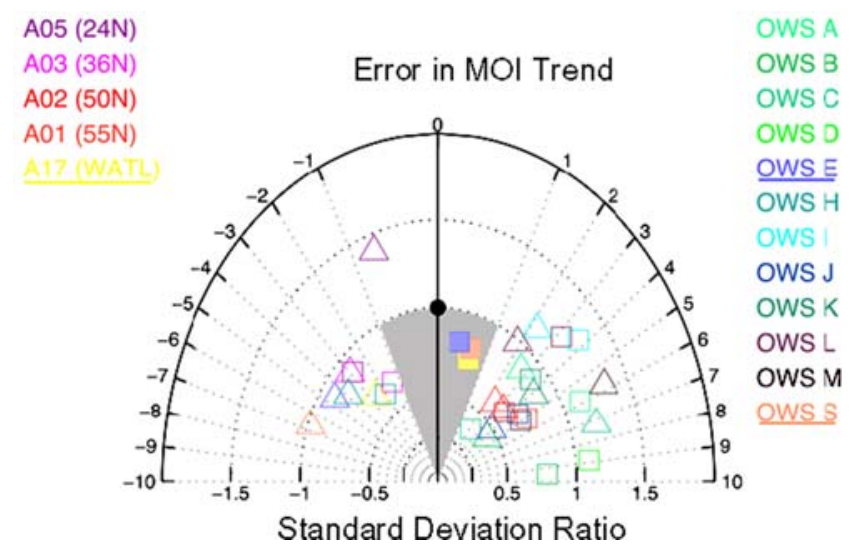

Fig. 11 Difference between modeled and constructed MOI trend versus constructed MOI variability for the years 2000-2100 AD. The model integration has standard deviation one and matches by definition the trend for the period 2000-2100 (black circle). Deviations from this trend based on temperatures are displayed by rectangles; salinity-based reconstructions by triangles. Section A17, station data OWS E and OWS S (temperature), and section A05 (salinity) show a close correspondence with the modeled MOI trend (errors less than $1 \mathrm{~Sv}$ per century) and in the case of the temperaturederived MOI (grey area), less variability than the simulated MOI 
small-scale signals. In the MOC reconstructions, which are based on hydrographic fields, one has to implicitly assume that the noisy signals are filtered out when considering monthly means or seasonal averages (when considering observations) or in the case of models that the net effect of eddies are well captured in current non-eddy resolving climate models.

\section{Conclusions}

Paleoceanographic proxy records indicate a strong relationship between MOC strength and mid-depth tropical Atlantic temperatures during the last deglaciation and Holocene millennial variability (Rühlemann et al. 2004). In our analysis, we see that a similar relationship helps to detect recent and future changes of the MOC. The temperature indicators suggest no MOC trend for the past 100 years using the existing long-term observations from the OWS. Our use of a spatial (albeit extremely coarse) network of hydrographic observations opens the prospect of MOC analysis beyond single latitude transects.

As implied from our work, improving the ocean observation system is critical for detecting the beginning of any MOC weakening. The almost-century-long data sets from the ocean weather ships put recent direct MOC measurements and possible future MOC changes into a long-term perspective. Therefore, the continuation of these measurements would constitute one important element of a MOC observing system. Furthermore, other quantities like the ocean heat transport can be analyzed in the same way as MOC trends. Drijfhout and
Hazeleger (2006) found out that the ocean heat transport depends not only on MOC but also on vertical temperature contrasts, which may compensate for a weaker MOC.

As a logical next step, the assimilation of ocean observing systems provides a dynamical interpolation and synthesis of hydrographic data sets. Unfortunately, the ocean observing systems based on satellite altimetry, ARGO profiling floats, XBT, and CLIVAR hydrography, do not cover many decades, which makes an estimate of MOC trends with respect to the last century and their relation to decadal to interdecadal MOC variability difficult. Alternatively, one may use the information of welldated, high-resolution proxy data. Lohmann et al. (2004) used high-resolution data from Cariaco Basin $\left(64.67^{\circ} \mathrm{W}\right.$, $10.5^{\circ} \mathrm{N}$; Black et al. 1999), covering the last 800 years in order to trace variations in MOC in terms of the interhemispheric sea surface temperature signature, which is consistent with the temperature reconstruction for the multiproxy network utilized by Mann et al. (1998). The proxy records show large interdecadal variations with no pronounced trend. A more detailed analysis of the mechanisms related to variations in MOC (Dima and Lohmann 2007) emphasizes a coupled atmosphere-ocean-sea ice mode, including an atmospheric wave-number-one pattern and sea ice transport on multidecadal time scales. It is conceivable that more high-resolution proxy data in sensitive regions may become available in order to trace past MOC variations and trends. In the future, a detailed analysis of the underlying physics influencing the effectiveness of such factors on MOC trends will be tested also in comparison with other coupled climate models.
Fig. 12 Reconstructed MOI time evolution based on temperature observations of OWS E (red) and OWS S (black). Simulated MOI based on these sites OWS E (blue) and OWS S (yellow) reveal a weakening of the MOC in the next century. The regression lines indicate the respective linear trends. For comparison, the anomalous meridional overtuning calculations plus error bars of Bryden et al. (2005) are included (green)

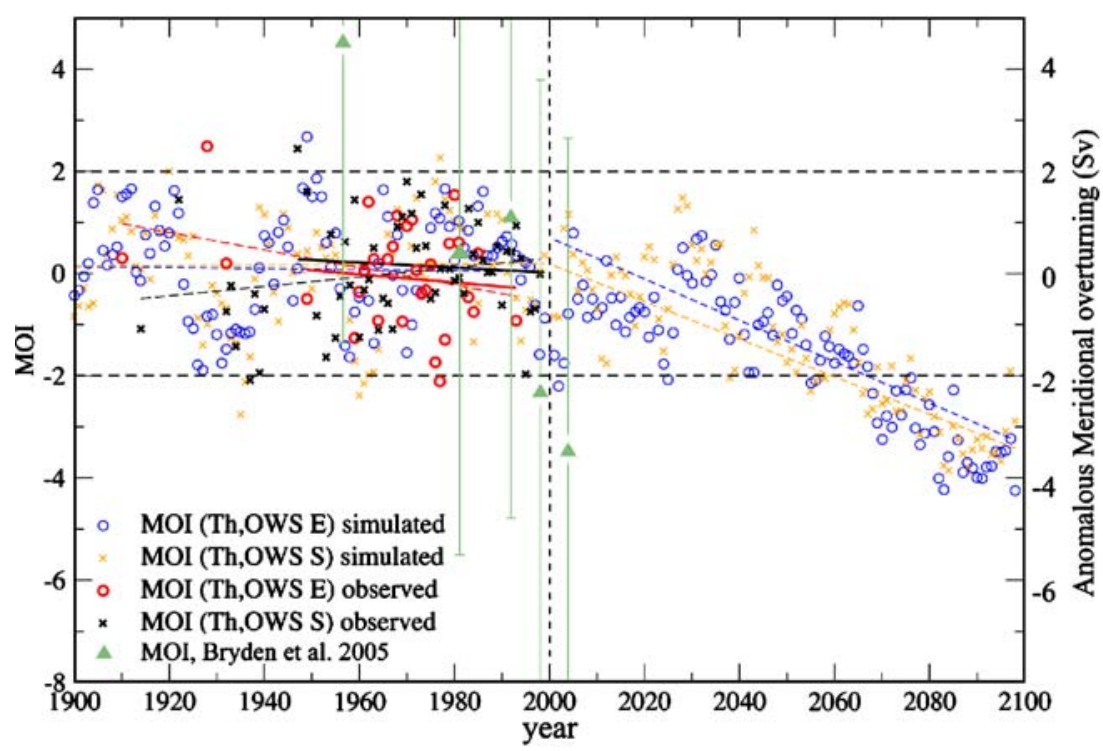


Acknowledgments We thank R. Curry for making the observational data available to us. We are thankful for constructive suggestions by three anonymous referees. The model simulations were done at the German Climate Computing Center (DKRZ) in Hamburg.

Open Access This article is distributed under the terms of the Creative Commons Attribution Noncommercial License which permits any noncommercial use, distribution, and reproduction in any medium, provided the original author(s) and source are credited.

\section{References}

Alley RB, Marotzke J, Nordhaus WD, Overpeck JT, Peteet DM, Pielke RA Jr., Pierrehumbert RT, Rhines PB, Stocker TF, Talley LD, Wallace JM (2003) Abrupt climate change. Science 299:2005-2010 doi:10.1126/science.1081056

Arbic BK, Owens WB (2001) Climate warming of Atlantic intermediate waters. J Climate 14:4091-4108

Baehr J, Hirschi J, Beismann JO, Marotzke J (2004) Monitoring the meridional overturning circulation in the North Atlantic: A model-based array design study. J Mar Res: 62(3):283-312

Baehr J, Keller K, Marotzke J (2007a) Detecting potential changes in the meridional overturning circulation at $26^{\circ} \mathrm{N}$ in the Atlantic. Clim Change, http://www.dx.doi.org/10.1007/s10584-006-9153-z

Baehr J, Haak H, Alderson S, Cunningham SA, Jungclaus JH, Marotzke J (2007b) Timely detection of changes in the meridional overturning circulation at $26^{\circ} \mathrm{N}$ in the Atlantic. J Clim 20:5827-5841

Black DE, Peterson LC, Overpeck JT, Kaplan A, Evans MN, Kashgarian M (1999) Eight centuries of North Atlantic Ocean atmosphere variability. Science 286:1709-1713

Broecker WS, Denton GH (1989) The role of ocean-atmosphere reorganizations in glacial cycles. Geochim Cosmochim Acta $53: 2465-2501$

Bryden HL, Longworth HR, Cunningham SA (2005) Slowing of the Atlantic meridional overturning circulation at $26.5^{\circ} \mathrm{N}$. Nature 438:655-657

Cunningham SA, Alderson S (2007) Transatlantic temperature and salinity changes at $24.5^{\circ} \mathrm{N}$ from 1957 to 2004 . Geophys Res Lett 34:L14606

Cunningham SA, Kanzow T, Rayner D, Baringer MO, Johns WE, Marotzke J, Longworth HR, Grant EM, Hirschi JJ-M, Beal LM, Meinen CS, Bryden HL (2007) Temporal variability of the Atlantic meridional overturning circulation at $26.5^{\circ} \mathrm{N}$. Science $317: 935-938$

Curry RG (2002) HydroBase2: a global database of hydrographic profiles and tools for climatological analysis. http://www.whoi. edu/science/PO/hydrobase

Curry R, Mauritzen C (2005) Dilution of the northern North Atlantic Ocean in recent decades. Science 308:1772-1774

Curry R, Dickson B, Yashayaev I (2003) A change in the freshwater balance of the Atlantic Ocean over the past four decades. Nature 426:826-829

Delworth TL, Dixon KW (2000) Implications of the recent trend in the Arctic/North Atlantic oscillation for the North Atlantic thermohaline circulation. J Climate 13:3721-3727

Dickson B, Yashayaev I, Meincke J, Turrell B, Dye S, Holfort J (2002) Rapid freshening of the Deep North Atlantic Ocean over the past four decades. Nature 416:832-837

Dima M, Lohmann G (2007) A hemispheric mechanism for the Atlantic multidecadal oscillation. J Climate 20:2706-2719

Drijfhout SS, Hazeleger W (2006) Changes in MOC and gyre-induced Atlantic Ocean heat transport. Geophys Res Lett 33:L07707 doi:10.1029/2006GL025807
Ganachaud A (2003) Error budget of inverse box models: The North Atlantic. J Atmos Ocean Technol 20:1641-1655

Ganachaud A, Wunsch C (2000) Improved estimates of global ocean circulation, heat transport and mixing from hydrographic data. Nature 408:453-456

Haak H (2004) Simulation of low-frequency climate variability in the North Atlantic Ocean and the Arctic. Reports on Earth System Science 1, Max Planck Institute for Meteorology, Hamburg, Germany, pp 115

Hirschi J, Baehr J, Marotzke J, Stark J, Cunningham S, Beismann J-O (2003) A monitoring design for the Atlantic meridional overturning circulation. Geophys Res Lett 30(7):1413

$\mathrm{Hu}$ A, Meehl GA, Han W (2004) Detecting thermohaline circulation changes from ocean properties in a coupled model. Geophys Res Lett 31:L13204 doi:10.1029/2004GL020218

Huybrechts P, Gregor J, Janssens I, Wild M (2004) Modelling Antarctic and Greenland volume changes during the 20th and 21 st centuries forced by GCM time slice integrations. Glob Planet Change 42:83-105

IPCC (2007) Intergovernmental panel on climate change. The physical basis of climate change (http://ipcc-wg1.ucar.edu/wg1/wg1report.html)

Jones PD, Osborn TJ, Briffa KR, Folland CK, Horton EB, Alexander LV, Parker DE, Rayner NA (2001) Adjusting for sampling density in grid box land and ocean surface temperature time series. J Geophys Res 106:3371-3380

Jungclaus JH, Haak H, Latif M, Mikolajewicz U (2005) Arctic-North Atlantic interactions and multidecadal variability of the meridional overturning circulation. J Climate 18:4013-4031

Jungclaus JH, Botzet M, Haak H, Keenlyside N, Luo J-J, Latif M, Marotzke J, Mikolajewicz U, Roeckner E (2006a) Ocean circulation and tropical variability in the coupled model ECHAM5/MPI-OM. J Climate 19:3952-3972

Jungclaus JH, Haak H, Esch M, Roeckner E, Marotzke J (2006b) Will Greenland melting halt the thermohaline circulation? Geophys Res Lett 33:L17708 doi:10.1029/2006GL026815

Kanzow $\mathrm{T}$ et al (2007) Observed flow compensation associated with the MOC at $26.5^{\circ} \mathrm{N}$ in the Atlantic. Science 317:938-941

Latif M, Roeckner E, Botzet M, Esch M, Haak H, Hagemann S, Jungclaus J, Legutke S, Marsland S, Mikolajewicz U, Mitchell J (2004) Reconstructing, monitoring, and predicting multidecadalscale changes in the North Atlantic thermohaline circulation with sea surface temperature. J Climate 17:1605-1613

Leadbetter SJ, Williams RG, McDonagh EL, King BA (2007) A twenty year reversal in water mass trends in the subtropical North Atlantic. Geophys Res Lett 34:L12608 doi:10.1029/ 2007GL029957

Levermann A, Griesel A, Hofmann M, Montoya M, Rahmstorf S (2005) Dynamic sea level changes following changes in the thermohaline circulation. Clim Dyn 24:347-354

Levitus S, Antonov JI, Boyer TP, Stephen C (2000) Warming of the world ocean. Science 287:2225-2229

Lohmann G (2003) Atmospheric and oceanic freshwater transport during weak Atlantic overturning circulation. Tellus 55A:438 449

Lohmann G, Rimbu N, Dima M (2004) Climate signature of solar irradiance variations: analysis of long-term instrumental, historical, and proxy data. Int J Climat 24:1045-1056

Mann ME, Bradley RS, Hughes MK (1998) Global-scale temperature patterns and climate forcing over the past six centuries. Nature 392:779-787

Marsland SJ, Haak H, Jungclaus JH, Latif M, Roske F (2003) The Max-Planck-Institute global ocean/sea ice model with orthogonal curvilinear coordinates. Ocean Modelling 5:91-127

McManus JF, Francois R, Gherardi J-M, Keigwin LD, Brown-Leger S (2004) Collapse and rapid resumption of Atlantic meridional 
circulation linked to deglacial climate changes. Nature 428: $834-837$

Rignot E, Kanagaratnam P (2006) Changes in the velocity structure of the Greenland ice sheet. Science 311:986-990

Roeckner E, Bäuml G, Bonaventura L, Brokopf R, Esch M, Giorgetta M, Hagemann S, Kirchner I, Kornblueh L, Manzini E, Rhodin A, Schlese U, Schulzweida U, Tompkins A (2003) The atmospheric general circulation model ECHAM 5. PART I: model description. MPI-Report 349, Max Planck Institute for Meteorology, Hamburg, Germany pp 127

Roemmich D, Wunsch C (1985) Two transatlantic sections: meridional circulation and heat flux in the subtropical North Atlantic Ocean. Deep-Sea Res 32(6):619-664

Rühlemann C, Mulitza S, Lohmann G, Paul A, Prange M, Wefer G (2004) Intermediate depth warming in the tropical Atlantic related to weakened thermohaline circulation: combining paleoclimate data and modeling results for the last deglaciation. Paleoceanography 19, PA1025, doi:10.1029/2003PA000948
Smethie WM Jr, Fine RA (2001) Rates of North Atlantic Deep Water formation calculated from chlorofluorocarbon inventories. DeepSea Res 48:189-215

Stouffer R, Yin J, Gregory JM, Dixon KW, Spelman MJ, Hurlin W, Weaver AJ, Eby M, Flato GM, Hasumi H, Hu A, Jungclaus JH, Kamenkovich IV, Levermann A, Montoya M, Murakami S, Nawrath S, Oka A, Peltier WR, Robitaille DY, Sokolov A, Vettoretti G, Weber N (2006) Investigating the causes of the response of the thermohaline circulation to past and future climate changes. J Climate 19:1365-1387

van Oldenborgh GJ, Philips SY, Collins M (2005) El Niño in a changing climate: a multi model study. Ocean Sci 1:81-95

Vellinga M, Wood RA (2004) Timely detection of anthropogenic change in the Atlantic meridional overturning circulation. Geophys Res Lett 31:L14203 doi:10.1029/2004GL020306

Von Storch J-S, Haak H (2008) Impact of daily fluctuations on longterm predictability of the Atlantic meridional overturning circulation. Geophys Res Lett 35:L01609 doi:10.1029/2007GL032385 